\title{
Morphology and classification of complete atrioventricular defects
}

\author{
GIAN PIERO PICCOLI ${ }^{1}$, JAMES L. WILKINSON, FERGUS J. MACARTNEY ${ }^{2}$, \\ LEON M. GERLIS, AND ROBERT H. ANDERSON ${ }^{2}$ \\ From the Department of Paediatrics, Cardiothoracic Institute, Brompton Hospital, London; \\ Institute of Child Health, University of Liverpool, Liverpool; Thoracic Unit, The Hospital for Sick \\ Children, Great Ormond Street, London; and Department of Pathology, Grimsby General Hospital, \\ South Humiberside
}

SUMMARY Anatomical studies were made on 70 necropsied hearts with atrioventricular defects from patients with situs solitus and atrioventricular concordance, all having a common atrioventricular orifice. The arterial connections were concordant in 68 and were double outlet right ventricle in two; cases with arterial discordance (transposition) or single outlet of the heart were excluded. It proved possible to subdivide the hearts, depending on the morphology of the valve leaflets. Five leaflets were distinguished by the commissural pattern and their insertion to major papillary muscles. They were a posterior bridging leaflet, right and left lateral leaflets, and right and left anterior leaflets. Subdivision was made on the basis of the disposition of the anterior leaflets. In six hearts the left anterior leaflet was committed to the left ventricle and the right anterior leaflet to the right ventricle, the commissure between them being on the crest of the ventricular septum. In 39 hearts there was minimal bridging of the left anterior leaflet so that it extended between the anterior papillary muscle of the left ventricle and the medial papillary complex of the right ventricle. In eight hearts the right margin of the left anterior leaflet was attached to an apical papillary muscle, while in 17 hearts it was attached to the anterolateral papillary muscle of the right ventricle. As the bridging of the left anterior leaflet increased, so the size of the right anterior leaflet decreased, but in all hearts both leaflets were identified. These findings were compared with previous classifications of complete atrioventricular defects.

The anatomical features of complete atrioventricular defects have been outlined by many authors who pointed out the shortness of the ventricular inlet segments (Rogers and Edwards, 1948; Wakai and Edwards, 1956, 1958; Goor et al., 1968; Blieden et al., 1974) and the excessive length of the outflow tract of the left ventricle (Van Mierop et al., 1962; Van Mierop and Alley, 1966; Gerbode et al., 1967; Van Mierop, 1977). Many investigators have also studied the constitution of the valve leaflets but it is the classification of Rastelli et al. (1966, 1967, 1968) based on the arrangements of the anterior leaflets which is most accepted by surgeons.

However, more recent papers have suggested a lack of correspondence between the surgical value of Rastelli's classification and the actual arrangement

\footnotetext{
${ }^{1}$ G. P. P. was a visiting fellow from Ospedale GM Lancisi, Ancona, Italy.

${ }^{2}$ F. J. M. and R. H. A. are supported by the British Heart Foundation together with the Vandervell Foundation and the Joseph Levy Foundation, respectively.

Received for publication 20 December 1978
}

of the leaflets of the common atrioventricular valve (Tenckhoff and Stamm, 1973; Goor and Lillehei, 1975; Ugarte et al., 1976), while Berger et al. (1978) have gone so far as to question its surgical value.

We have analysed 70 specimens of complete atrioventricular defects from an anatomical point of view, excluding any embryological interpretations, and findings relative to these disagreements are presently described.

\section{Subjects and methods}

Seventy specimens with complete atrioventricular defects were analysed. They were taken from the pathological collections of the Brompton Hospital, London; The Hospital for Sick Children, London, The Royal Liverpool Children's Hospital; Grimsby General Hospital, South Humberside; and the Department of Paediatric Pathology, University of Sheffield. In all specimens we studied the anatomy of the valve leaflets according to the criteria of Lam et al. (1970), Ranganatham et al. (1970), 
and Silver et al. (1971), the anatomical disposition of the papillary muscles in the right ventricle, and the modality of insertion of the interatrial septum primum at the atrioventricular level.

All the specimens except two were in situs solitus with concordant atrioventricular connection and normal relation of cardiac chambers and great arteries. The two outstanding cases had double outlet right ventricle with the aortic valve in right posterior position.

\section{Results}

In all the hearts examined, five leaflets could be identified in the common valve on the basis of the papillary muscle tethering (Fig. 1). They were a posterior bridging leaflet, a left lateral and right lateral (or inferior) leaflet, and two anterior leaflets. The lateral leaflets showed various degrees of 'scalloping' which, in some instances, was suffi-
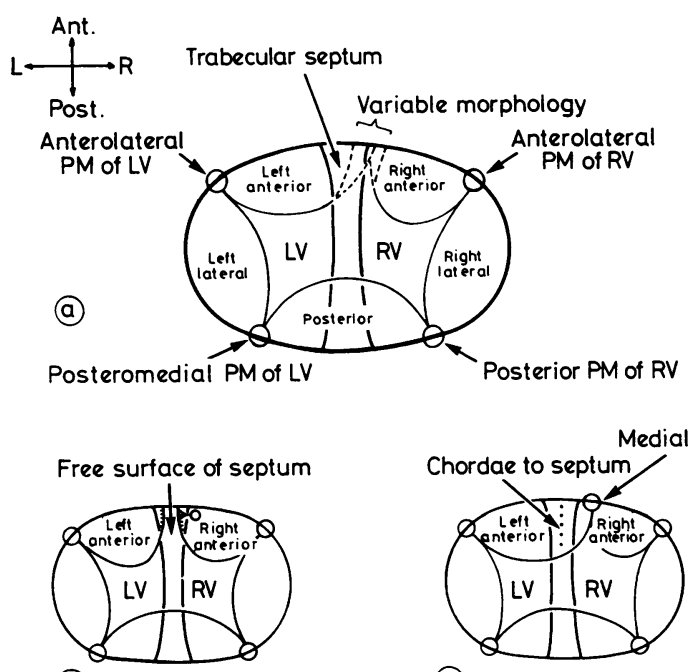

(b)
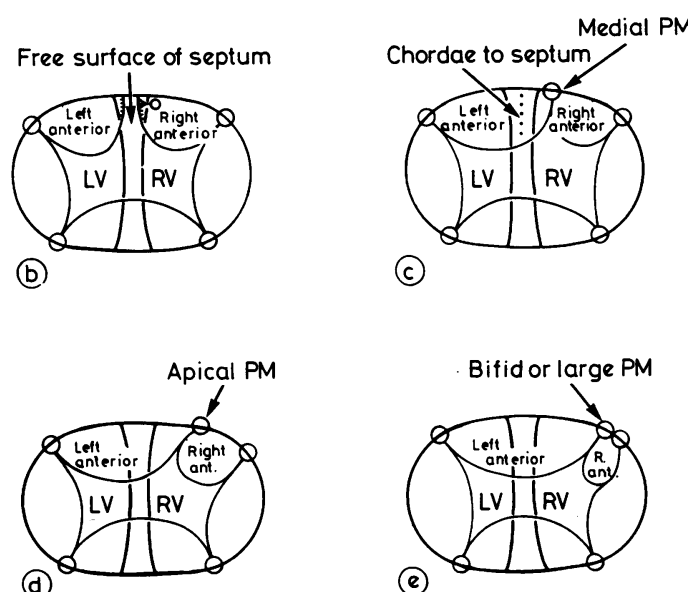

Fig. 1 Diagram illustrating the variation of the anterior leaflets of complete atrioventricular defects. Fig. 1a shows the position of the leaflets and their supporting papillary muscles. Fig. 1b-1e illustrate the varying morphology of the malformations studied. ciently obvious to suggest the presence of an additional leaflet. However, it was the variation in morphology of the two anterior leaflets which provided the basis for subdivision of the hearts.

\section{ANTERIOR LEAFLETS COMMITTED TO RIGHT AND LEFT VENTRICLES, RESPECTIVELY} (Fig. 1b)

In six cases, the left anterior leaflet extended between the anterolateral papillary muscle of the left ventricle and the crest of the ventricular septum to which it was attached by multiple chordae. The right anterior leaflet extended from the crest of the septum to the anterolateral papillary muscle of the right ventricle, which also supported the right lateral leaflet. The medial papillary muscle complex supported the medial end of the right anterior leaflet, but the crest of the ventricular septum between the leaflet was bare, that is was not bridged by leaflet tissue (Fig. 2).

\section{BRIDGING LEFT ANTERIOR LEAFLET TO}

MEDIAL PAPILLARY MUSCLE (Fig. 1C)

In 39 cases the left anterior leaflet exterded from the anterolateral papillary muscle of the left ventricle to the medial papillary muscle which arose in normal fashion from the posterior limb of the trabecula septomarginalis (Fig. 3). There was variation in the relation of this bridging leaflet to the septal structures. In 33 hearts the leaflet was attached by vertical chords to the trabecular septum as it bridged this septum. In the majority of these hearts, a partially formed interventricular component of the membranous septum joined the bridging leaflet to the infundibular septum, with a portion of the leaflet in the right ventricle (Fig. 3b). The anterior insertion of the atrial septum was in line with the trabecular septum and the interventricular membranous septum, that is to the left of the commissure between the two anterior leaflets (Fig. 3c). There was a discrete commissure between the two anterior leaflets supported by the medial papillary muscle complex. In four additional hearts, the bridging leaflet was not tethered to the trabecular septum but was attached to the infundibular septum via the membranous septal remnant. In the final two hearts, the bridging leaflet was attached only to the medial papillary muscle, having no attachment to the ventricular septum. In all these hearts the right anterior leaflet extended from the medial papillary complex to the anterolateral papillary muscle of the right ventricle. In five of these, an additional bar of muscle extended from the anterolateral muscle mass to the free margin of the leaflet. 


\section{BRIDGING LEFT ANTERIOR LEAFLET TO}

APICAL PAPILLARY MUSCLE (Fig. 1d)

In eight cases, the left anterior leaflet extended from the anterolateral papillary muscle of the left ventricle across the trabecular septum to be attached to a papillary muscle situated on the right ventricular septal surface, towards the ventricular apex (Fig. 4, 5). This muscle supported the commissure between the left anterior and right anterior leaflets, the latter leaflet being smaller in

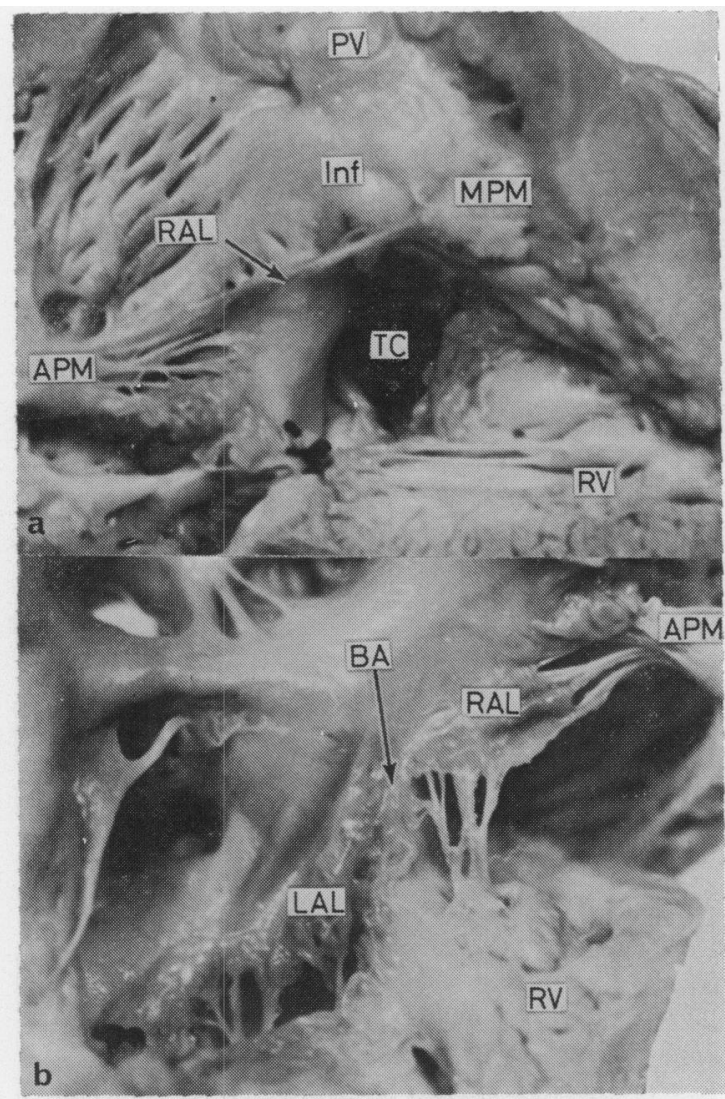

Fig. 2 An example of an atrioventricular defect of the type shown diagrammatically in Fig. $1 b$. Fig. $2 a$ shows the view of the right side of the common valve (TC) observed from the infundibular aspect. The right anterior leaflet ( $R A L$ ) extends from the medial papillary muscle (MPM) to the anterior papillary muscle ( $A P M$ ) of the right ventricle ( $R V)$. (Inf, infundibulum; PV, pulmonary valve). Fig. $2 b$ shows a view of the anterior leaflets of the common valve viewed posteriorly from the right atrioventricular junction. The left anterior leaflet ( $L A L$ ) and the right anterior leaflet are both attached to the septal crest leaving the free surface of the septum bare between their attachments (BA). (Other abbreviations as before.)

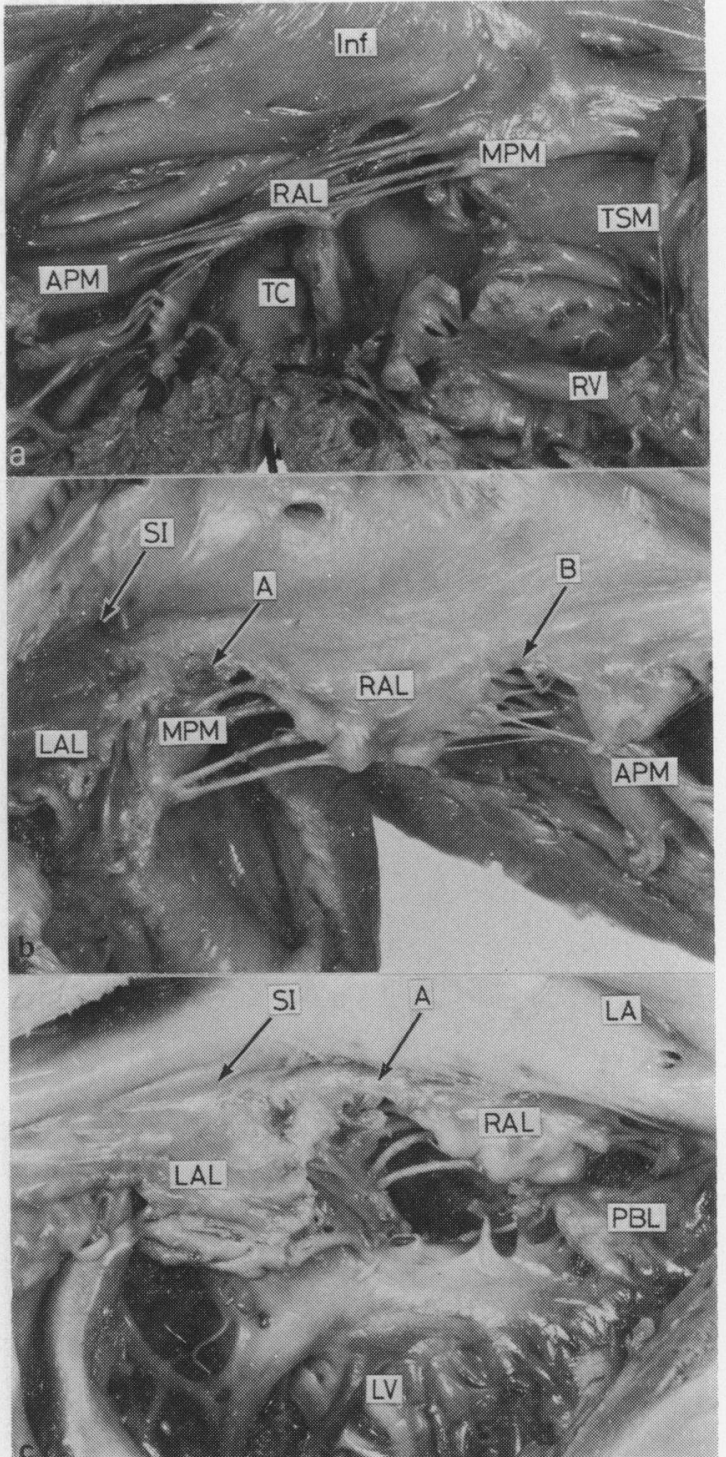

Fig. 3 Photograph of a specimen illustrating the morphology of the leaflets shown diagrammatically in Fig. 1c. Fig. 3a shows the infundibular view. The right anterior leaflet is again seen extending between anterior and medial papillary muscles. (TSM, trabecular septomarginalis). Fig. $3 b$ shows the leaflets from their right posterior aspect and illustrates how the left anterior leaflet has bridged the septum to be attached by commissural chord $A$ to the medial papillary muscle. The commissure $B$ taking origin from the right anterior papillary muscle is between the right anterior and right lateral leaflets. Note that the insertion of the atrial septum is well to the left of commissure $A$ between the anterior leaflets. Fig. $3 c$ shows the leaflets viewed from their left posterior aspect. ( $L V$, left ventricle; $L A$, left atrium; $P B L$, posterior bridging leaflet; other abbreviations as before.) 
size compared with the group in which it was attached to the medial papillary muscle complex. In three of them, the left anterior leaflet was attached to the infundibular septum by a remnant of the interventricular membranous septum. None had chordal attachments to the septum, that is the bridging leaflet was 'free-floating'. In this group there was variation in the size of the papillary muscle supporting the anterior commissure, between a single large muscle and multiple small muscles. However, all were attached towards the apex, in

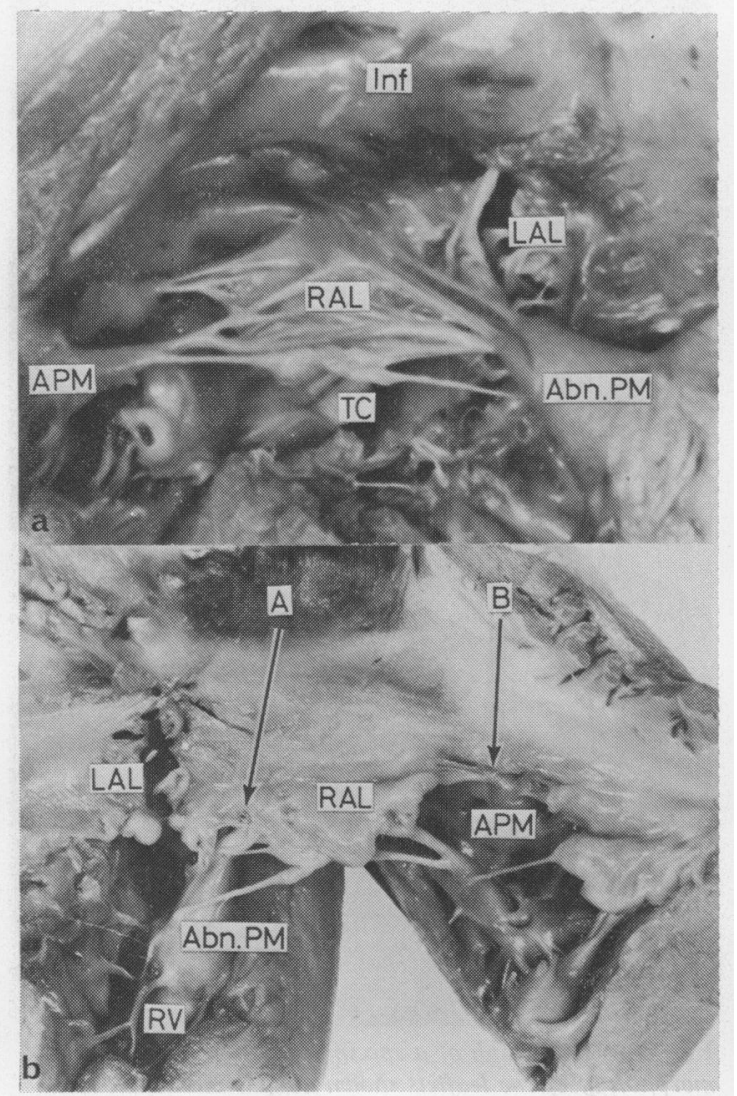

Fig. 4 Photographs illustrating the morphology illustrated diagrammatically in Fig. 1d. Fig. 4a shows the infundibular view. The left anterior leaflet again bridges the septum but the commissural chord between it and the right anterior leaflet is attached to an abnormal papillary muscle situated on the right ventricular septal surface (Abn. PM). Fig. $4 b$ shows the right posterior view of these leaflets. The left anterior leaflet bridges to a greater extent than in the heart illustrated in Fig. 3. The right anterior leaflet in contrast is smaller than the heart shown in Fig. 3. This specimen had been repaired surgically. The stitches in the left anterior leaflet were for reconstitution of this leaflet. (Other abbreviations as before.) comparison with the normal medial papillary complex and neither a 'normal' medial muscle nor a trabecula septomarginalis was identified in any cases. The apical muscles all showed a tendency to approximate the anterolateral muscle, were well formed, and supported the commissure between the right anterior and the right lateral leaflets (Fig. 4, 5).

\section{BRIDGING LEFT ANTERIOR LEAFLET TO}

CONJOINED ANTEROLATERAL MUSClE (Fig. le) In 17 cases, the left anterior leaflet extended from

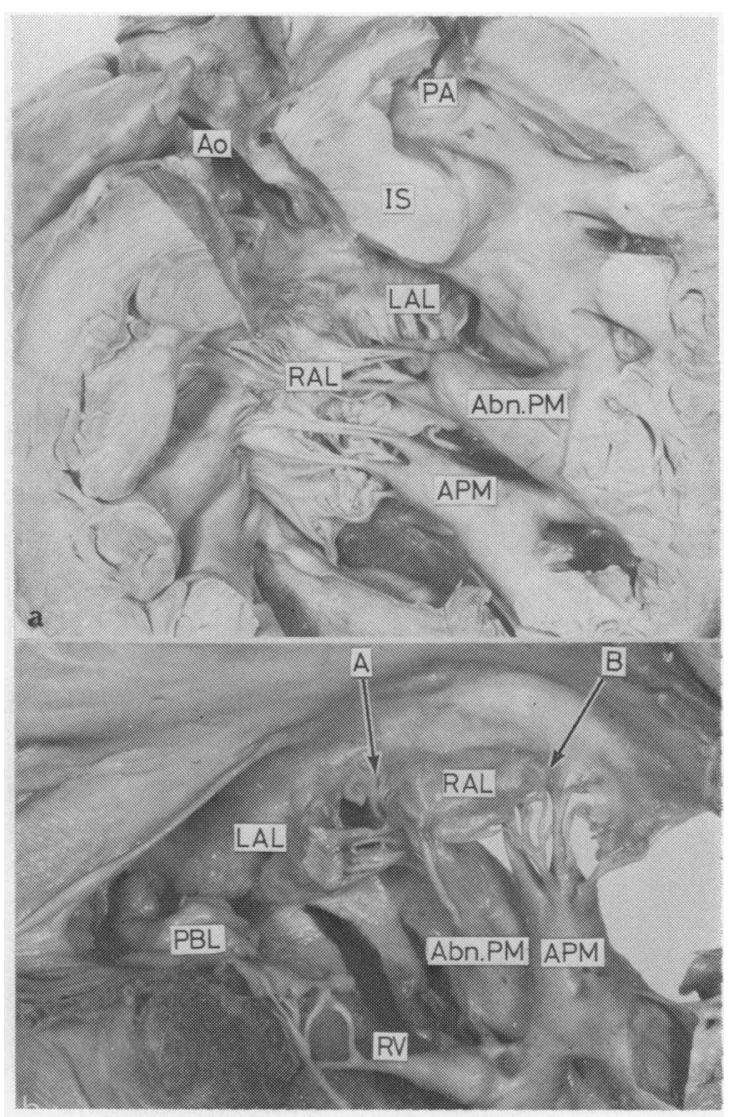

Fig. 5 Photographs of another heart illustrating the morphology shown diagrammatically in Fig. 1d. In this heart the abnormal papillary muscle supporting the commissure between the anterior leaflets is much closer to the anterior papillary muscle supporting the commissure $B$ between the right anterior and lateral leaflets. Fig. $5 a$ shows the infundibular view and Fig. $5 b$ the right posterior view of this heart. The ventriculoarterial connection was double outlet right ventricle. This is illustrated in Fig. 5a where both the aorta (Ao) and pulmonary artery $(P A)$ are seen arising from the right ventricle, their origins separated by the infundibular septum (IS). (Other abbreviations as before.) 
the left anterolateral papillary muscle of the left ventricle to the anterolateral muscle group of the right ventricle. This muscle group of the right ventricle in all cases was bifid, and supported two discrete commissures. One commissure was formed between the two anterior leaflets, the other between the right anterior leaflet, which was considerably reduced in size, and the right lateral leaflet (Fig. 6, 7). The pattern of the conjoined right anterolateral muscle varied, but two commissural chords were

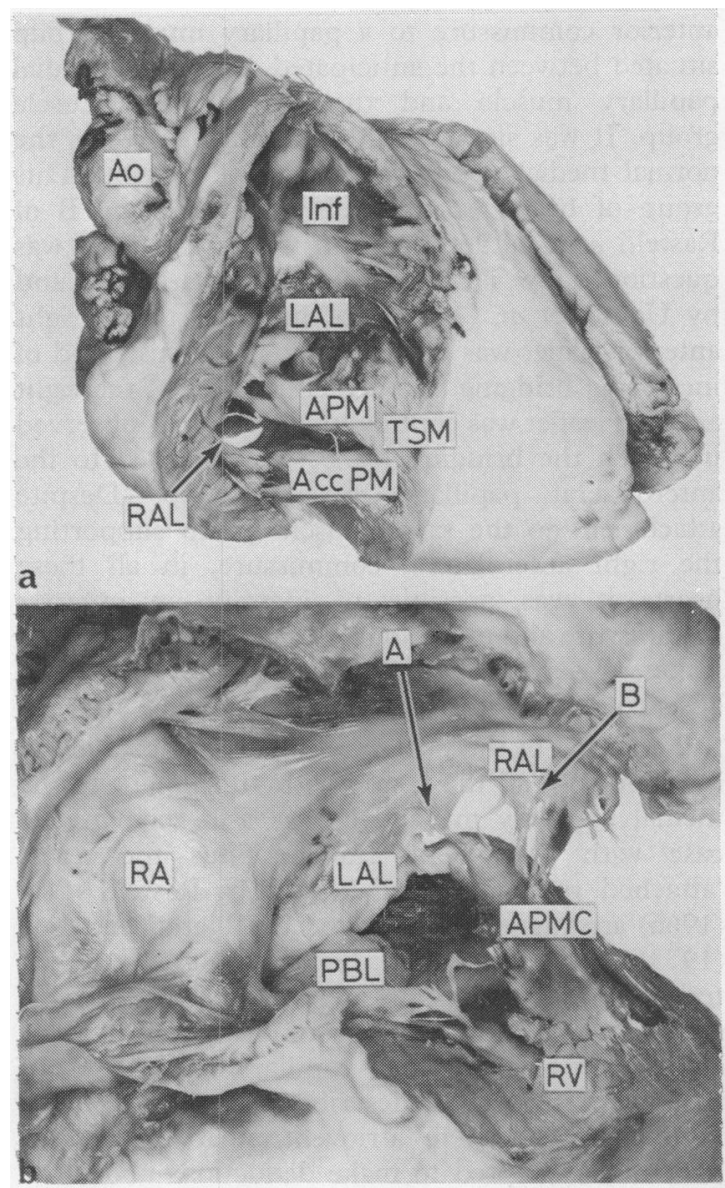

Fig. 6 Photograph illustrating the morphology shown diagrammatically in Fig. 1e. In this heart the commissures between both the left anterior and the right anterior and between the right anterior leaflet and the right lateral leaflet (commissures $A$ and $B$ ) are both supported by the anterior papillary muscle ( $A P M)$ together with an accessory papillary muscle (Acc PM). When viewed from the posterior aspects (Fig. $6 \mathrm{~b}$ ) these two muscles together form an anterior papillary muscle complex (APMC). The right anterior leaflet is still smaller in this heart and comparison with Fig. 2-5 will illustrate a spectrum of malformations, depending on the position of the papillary muscle supporting commissure $A$. always identified (Fig. 7b). As the left anterior leaflet bridged the septum, it was attached to the infundibular septum by the membranous septal remnant in three cases. In all cases but one the leaflet was unattached with reference to the trabecular septum (free floating). In none of these cases was it possible to identify papillary apparatus comparable with the normal medial papillary muscle complex (Fig. 6, 7).

\section{POSTERIOR BRIDGING LEAFLET}

In all cases the posterior leaflet was common to both right and left ventricles. In 59 cases, the posterior leaflet was firmly attached at the crux, but became free as it passed anteriorly, part of the ventricular septal defect being beneath the leaflet. However, in no case was the leaflet entirely free

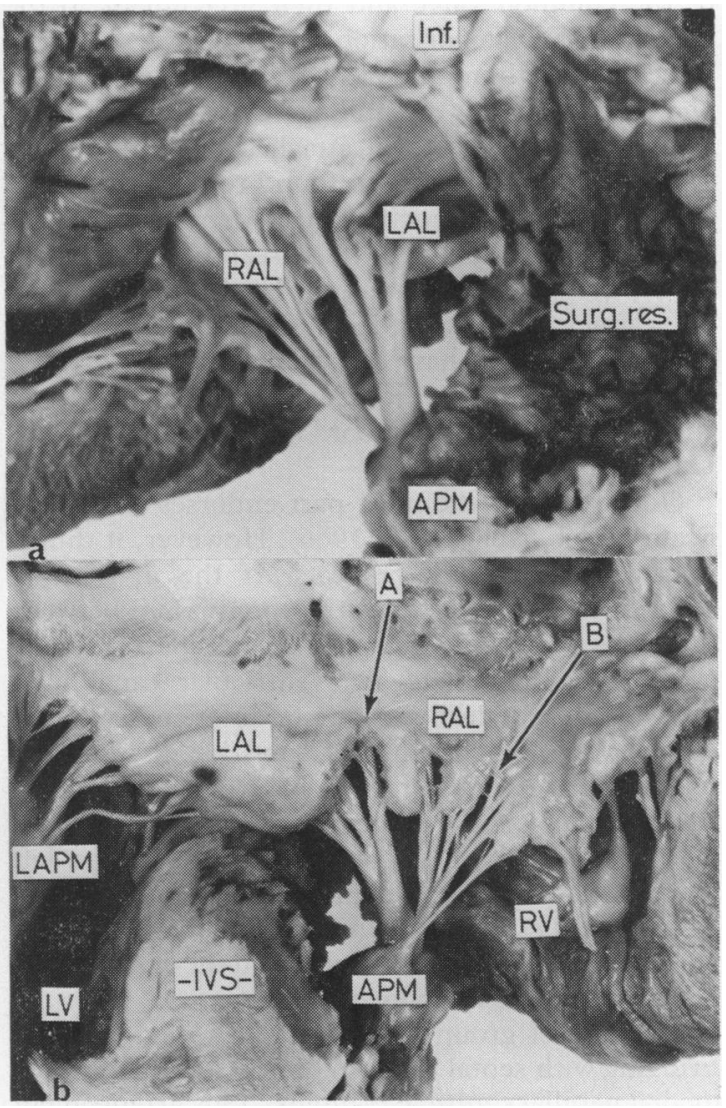

Fig. 7 Photographs of another heart illustrating the morphology shown diagrammatically in Fig. 1e. In this heart a single anterior papillary muscle supports commissures $A$ and $B$. The right anterior leaflet is cleft. Fig. $7 a$ is viewed from the infundibulum and Fig. $7 b$ shows a posterior view with transection of the interventricular septum (IVS). There has been surgical resection (Surg res) of the infundibulum in this case. 
floating. In the other 11 cases, the leaflet was firmly attached to the inlet septum throughout its extent. The posterior leaflet always extended between the posteromedial papillary muscle of the left ventricle and the posterior papillary muscle of the right ventricle. There was no correlation between the morphology of the posterior and anterior bridging leaflets.

\section{Discussion}

We have described in the previous paper (Piccoli et al., 1979) the basic anatomical features of atrioventricular defects. The cases described here are examples of the complete form. This variety has previously been subdivided according to the variation in leaflet pattern of the anterior components of the common valve and their attachment to the septum. The categorisation of Rastelli et al. (1966) into forms with an attached divided anterior leaflet and a free-floating common anterior leaflet, with a rare intermediate form attached to an abnormal papillary muscle, has been found to be of immense value in surgical practice (McGoon et al., 1973; Pacifico and Kirklin, 1973; Alfieri and Subramanian, 1975), though more recently it has been questioned by Berger et al. (1978). Furthermore, recent anatomical studies have cast doubt upon the validity of the classification (Goor et al., 1968; Tenckhoff and Stamm, 1973; Goor and Lillehei, 1975; Ugarte et al., 1976).

Our study for the most part endorses the classification of Rastelli et al. (1966). However, it differs in several important respects. If the division of anterior leaflets is taken as the commissure between the left anterior and right anterior leaflets, then all examples of complete atrioventricular canal have divided anterior leaflets. Our findings indicate that on the basis of commissural position it is always possible to distinguish two anterior leaflets, two lateral leaflets, and a posterior leaflet. The variation in morphology relates to whether or not the left anterior leaflet bridges the trabecular septum. When it does bridge, then further variation depends on its degree of bridging, its septal tethering, and its papillary muscle attachment.

The largest group in our series showed minimal bridging with septal tethering but attachment to the medial papillary muscle complex. This arrangement was described by Rastelli et al. (1966) but their lllustration for this type shows a heart with the ieft anterior leaflet committed entirely to the left ventricle. We observed only six such hearts in our series. That bridging occurs in the great majority of our hearts is attested to by the attachment of the left anterior leaflet to the medial papillary complex (a feature also observed by Ugarte et al., 1976); in addition, the attachment of the bridging leaflet by chordae to the septal crest, the presence of a membranous septal remnant dividing the left anterior leaflet into left ventricular and right ventricular components, and the attachment of the atrial septum to the left of the anterior commissure are all measures of the degree of rightward extension of the left anterior leaflet.

Increased bridging of the left anterior leaflet was associated in our series with attachment of the anterior commissure to a papillary muscle group situated between the anticipated side of the medial papillary muscle and the anterolateral muscle group. It was significant that in all these cases the normal medial papillary muscle was absent. This group of hearts corresponds with the type B of Rastelli et al. (1966), a form whose existence was questioned by Tenckhoff and Stamm (1973) and by Ugarte et al. (1976). In these hearts the right anterior leaflet was decreased in size. This trend of increasing bridging and decreasing size of the right anterior leaflet was continued in the hearts observed in which the bridging leaflet was attached to the anterolateral papillary muscle group. Despite attachment to the same muscle group supporting the right anterolateral commissure, in all these hearts it was possible to identify an anterior commissure and to distinguish a small right anterior leaflet. The medial papillary muscle was again absent in these hearts.

Tethering of the bridging leaflet was observed in most but not all the hearts with attachment to the medial papillary muscle. It was also seen in one case with a bridging leaflet. Thus the terms 'attached' or 'unattached' as used by Rastelli et al. (1966) are vague. As indicated by Bharati and Lev (1973), attachment can be via chordae to the trabecular septum, via a membranous septal remnant to the infundibular septum, or by commissural attachment to the medial papillary muscle. All of those can coexist. In describing these anatomical findings in complete atrioventricular defects we have not attempted to make deductions about the embryological significance of the observed variations. in leaflet morphology and papillary apparatus. From the surgical standpoint it is clear that the cusp tissue available for reconstruction of functional valves must be assessed individually at operation. There seems no reason to believe from our findings that any of the observed variations could preclude surgical repair, provided that both ventricles are of adequate size and sufficient cusp tissue is present. It seems clear, however, that the nature of the defect does imply that anatomically normal valves. could not be created and the surgeon should 
concentrate on finding ways of producing a functionally satisfactory valve rather than attempting to produce facsimiles of the normal mitral and tricuspid valves.

In conclusion, our results suggest that complete atrioventricular defects can be simply divided according to the attachment of the anterior leaflets of the valve, two in number. The differentiation is that the left anterior leaflet may be committed solely to the left ventricle or may bridge the septum to be attached to the medial papillary muscle, an apical papillary muscle, or the anterolateral papillary muscle group of the right ventricle With increased bridging of the left anterior leaflet, there is concomitant decrease in size of the right anterior leaflet.

\section{References}

Alfieri, O., and Subramanian, S. (1975). Successful repair of atrioventricular canal with undivided anterior common leaflet in a 6 month old infant. Annals of Thoracic Surgery, 19, 92-97.

Berger, T. J., Kirklin, J. W., Blackstone, E. H., Pacifico, A. D., and Kouchoukos, N. (1978). Primary repair of complete atrioventricular canal in patients less than 2 years old. American fournal of Cardiology, 41, 906-913.

Bharati, S., and Lev, M. (1973). The spectrum of common atrioventricular orifice (canal). American Heart fournal, 86, 553-561.

Blieden, L. C., Randall, P. A., Castaneda, A. R., Lucas, R. V., jun, and Edwards, J. E. (1974). The 'goose neck' of the endocardial cushion defect: anatomic basis. Chest, 65, 13-17.

Gerbode, F., Sanchez, P. A., Arguero, R., Kert, W. H. Hile, J. D., de Vries, P. A., Seller, A., and Robinson, S. J. (1967). Endocardial cushion defects. Annals of Surgery, 166, 487-495.

Goor, D. A., and Lillehei, C. W. (1975). Atrioventricular canal malformations. In Congenital Malformations of the Heart, p. 132. Grune \& Stratton, New York.

Goor, D., Lillehei, C. W., and Edwards, J. E. (1968). Further observations on the pathology of the atrioventricular canal malformation. Archives of Surgery, 97, 954-962.

Lam, J. H. C., Ranganatham, N., Wigle, E. D., and Silver, M. D. (1970). Morphology of the human mitral valve. I. Chordae tendineae: a new classification. Circulation, 41, 449-458.

McGoon, D. C., McMullan, M. H., Mair, D. G., and Danielson, G. K. (1973). Correction of complete atrioventricular canal in infants. Mayo Clinic, Proceedings, 48, 769-772.

Pacifico, A. D., and Kirklin, J. W. (1973). Surgical repair of complete atrioventricular canal with anterior common leaflet attached to an anomalous right ventricular papillary muscle. Fournal of Thoracic and Cardiovascular Surgery, 65, 727-730.
Piccoli, G. P., Gerlis, L. M., Wilkinson, J. L., Lozsadi, Karolyi, Macartney, F. J., and Anderson, R. H. (1979). Morphology and classification of atrioventricular defects. British Heart fournal, 42, 621-632.

Ranganatham, N., Lam, J. H. C., Wigle, E. D., and Silver, M. D. (1970). Morphology of the human mitral valve. II. The valve leaflets. Circulation, 41, 459-467.

Rastelli, G. C., Kirklin, J. W., and Kincaid, O. W. (1967). Angiocardiography of persistent common atrioventricular canal. Mayo Clinic Proceedings, 42, 200-209.

Rastelli, G. C., Kirklin, J. W., and Titus, J. L. (1966). Anatomic observations on complete form of persistent common atrioventricular canal with special reference to atrioventricular valves. Mayo Clinic Proceedings, 41, 296-308.

Rastelli, G. C., Ongley, P. A., Kirklin, J. W., and McGoon, D. C. (1968). Surgical repair of the complete form of persistent common atrioventricular canal. Fournal of Thoracic and Cardiovascular Surgery, 55, 299-308.

Rogers, H. M., and Edwards, J. E. (1948). Incomplete division of the atrioventricular canal with patent interatrial foramen primum (persistent common atrioventricular ostium). American Heart fournal, 36, 28-36.

Silver, M. D, Lam, J. H. C., Ranganatham, N., and Wigle, E. D. (1971). Morphology of the human tricuspid valve. Circulation, 43, 333-348.

Tenckhoff, L., and Stamm, S. J. (1973). An analysis of 35 cases of the complete form of persistent common atrioventricular canal. Circulation, 48, 416-427.

Ugarte, M., Salamanca, E. F., and Quero, M. (1976). Endocardial cushion defects. An anatomical study of 56 specimens. British Heart fournal, 38, 674-682.

Van Mierop, L. H. S. (1977). Pathology and pathogenesis of endocardial cushion defects. Surgical implications. In Second Henry Ford Hospital International Symposium on Cardiac Surgery, pp. 201-207, ed J. C. Davila. Appleton-Century-Crofts, New York. Van Mierop, L. H. S., and Alley, R. D. (1966). The management of the cleft mitral valve in endocardial cushion defects. Annals of Thoracic Surgery, 2, 416423.

Van Mierop, L. H. S., Alley, R. D., Kausel, H. W., and Stranahan, A. (1962). The anatomy and embryology of endocardial cushion defects. Fournal of Thoracic and Cardiovascular Surgery, 43, 71-83.

Wakai, C. S., and Edwards, J. E. (1956). Developmental and pathologic considerations in persistent common atrioventricular canal. Proccedings of the Staff Meetings of the Mayo Clinic, 31, 487-500.

Wakai, C. S., and Edwards, J. E. (1958). Pathologic study of persistent common atrioventricular canal. American Heart fournal, 56, 779-794.

Requests for reprints to Robert $H$. Anderson, Cardiothoracic Institute, Brompton Hospital, Fulham Road, London SW3 6HP. 